\title{
Strategic Discourse Around Open Source Governance in Asia
}

\author{
Shane Coughlan, ${ }^{a}$ \\ (a) Communication and Business \\ Development Professional; General \\ Assembly Member, Free Software \\ Foundation Europe and Board \\ Member, OpenForum Europe
}

DOI: $\underline{10.5033 / \text { ifosslr.v7i1.101 }}$

\begin{abstract}
Open Source governance in Asia is of importance for US and European technology businesses. However, the collaborative limits to formal contracts or international treaties require initiatives that facilitate the sharing of best practices in a manner more conducive to far reaching collaboration. With Asian companies increasingly visible around development in certain platform technologies, not least those related to mobile and cloud computing. the terrific opportunity that lies ahead for the global technology industry is to maximise collaboration. This article explains some initiatives that seek to bridge as much as possible the knowledge present in America, Europe and Asia so the most valuable ideas travel to all interested parties.
\end{abstract}

\section{Keywords}

Law; information technology; Free and Open Source Software; governance; compliance, Asia

Open Source governance in Asia - whether framed from the perspective of compliance, supply chain management or IPR strategy - is a frequently cited topic of importance and potential concern for US and European technology businesses. It encompasses a wide range of interests whether framed from the perspective of suppliers or Eastern competition. However, there has been a certain disconnect in facilitating on-going dialogue between the operating entities across the continents, and there is a limit to what formal contracts or international treaties can accomplish.

The collaborative limits to formal contracts or international treaties are precisely the reason that certain developments in the field of Open Source governance have proven to be so 
popular and lasting in the Americas and in Europe. Two critical examples are the Linux Foundation Member Counsel Meetings and the European Legal Network, both of which facilitate the sharing of best practices in a manner more conducive to far reaching platform engagement than might be facilitated during traditional market transactions.

Asian companies, while occasionally being part of the above two cited initiatives, have historically been removed from the front lines of international information sharing. Quite a few factors may be behind this, from generic "cultural differences" through to assertions that Asian businesses have a fundamentally different approach to time management and contribution. Discounting more eclectic opinions expressed about the matter, there is probably a kernel of truth in the concept that Asian companies, and in particular Asian professionals, face slightly different motivations, constraints and priorities than their American or European counterparts.

In countries such as Japan and Korea many legal or engineering professionals are closely tied to their companies. When careers advance through internal promotion, it tends to foster a close identification with the culture of one company and this in turn understandably imparts a close alignment with the expectations of that company. While platforms such as Linux may be adopted for cost and convenience reasons, the "DNA" of such corporations, and therefore the primary motivational forces behind employee advocacy and decisions, tends to be focused on company R\&D, products and ancillary services.

In countries such as China and much of the rest of the Asia-Pacific/South Asian region there is a higher rate of turnover in staff. Margins are extremely thin, competitive pressures are brutal, and companies appear to be in a race to the bottom in terms of pricing. While individual professionals in such an environment may be more willing to discuss new and better ways of doing things, if the underlying assumption is that time and resources exist to invest in a longterm manner, the explicit business requirements of their individual companies will make "ecosystem contribution" or "good citizenship" approaches a luxury that is simply unavailable.

Of course American and European companies have their differences in terms of both national concerns and larger trends on each continent. While capital and speculative investment may arguably have a tendency to be more readily available and more sustained in the USA compared to much of Europe, it could also be asserted that German and French companies may take a longer-view of engagement with platforms and partners compared to their American counterparts. Each approach has its advantages and disadvantages, and over time the better ideas tend to filter through businesses, sectors and geographies.

The question is therefore "why is it hard for ideas to filter back and forth between Western companies and Eastern companies?" We are facing a situation where communication is not necessarily as effective as it could be. This challenge is broader than Open Source or governance per se, but given that Open Source depends on collaboration for optimal efficiency, it defines the heart of the concern.

One answer to the question may be relatively simple. At meetings in Asia I am told that managers, lawyers and engineers perceive a certain inherent exclusion from discourse in fields such as Open Source. It is pointed out that assumptions regarding the use of English in programming, in strategy discussions and around legal discourse can be problematic. The leap for a German, Spanish or French speaker to discuss topics in English is far less than that which is required for a Chinese, Korean or Japanese native. This linguistic barrier remains a key item cited by Asia-Pacific company representatives for the hesitation or lack of 
engagement so often identified as an industry concern.

Building bridges between stakeholders has long been a speciality of community organisations such as Linux Foundation, Open Invention Network, Free Software Foundation Europe and the Software Freedom Law Center. The topic of Open Source governance in Asia and the concept of finding ways to provide more effective dialogue and information sharing has therefore hardly been unaddressed. There are activities under way that are helping to connect parties from the East and West regardless of language, regardless of individual priority, and with the overarching goal of encouraging a shared perception of engagement and participation.

A key example in Asia-Pacific is an understated but important conference held in Japan each year called the Open Compliance Summit. This event is hosted by Linux Foundation Japan under the supervision of their director Noriaki Fukuyasu, and during its three years of existence has developed an explicit policy of encouraging speakers from China, Korea and Taiwan to attend along with experienced figures from major Japanese corporations. The result is the first environment where all of these stakeholders can meet and informally discuss governance issues, and it has proven to be a compelling venue to reiterate key developments from Linux Foundation Member Counsel or European Legal Network activities. While the language used is still primarily English, the environment is designed to support those who use it as a second or third language.

The value of the Open Compliance Summit is that it is perhaps the first event in Asia that fosters an environment where attendees are not expected to simply listen to speeches from international figures but are instead asked "what do you think?" The responses in previous years have revealed interest, comments and suggestions for topics ranging from Linux Foundation's SPDX initiative through to compliance process management inside large companies. The event perhaps most closely aligned in terms of value and desired approach in the Western hemisphere is the European Legal Network Conference, and the Open Compliance Summit provides an excellent cornerstone from which to launch meaningful discourse around Open Source governance concerns in the APEC region.

One challenge for the Open Compliance Summit - beyond the complexity of using the English language as the primary method of discourse - is that it only happens once a year. In a fast moving field such as Open Source, and particularly given the recent climate both of new market development and various IPR challenges, governance topics tend to unfold and benefit from analysis on a more frequent basis. To address this issue, some key stakeholders from the community side of Open Source legal strategy - namely Open Invention Network, Linux Foundation and Free Software Foundation Europe - launched the Asian Legal Network in the first quarter of 2014.

The Asian Legal Network, building on the template provided by the European Legal Network in providing a forum for discourse via round-tables, mailing list and conference, is an initiative to facilitate round-table meetings once per quarter in the Asia-Pacific region. The meetings rotate from country to country, with the focus in the first year of operating being China, Japan and Korea (the CJK nations), and expansion expected in the second year to potentially include India along with increased support for country-specific language use during presentations and round-table discussions.

As with the European Legal Network, the Asian Legal Network is not a formal legal entity and it does not require any formal commitment either on behalf of the individuals 
participating nor their companies beside one "gentleman's rule", namely adherence to Chatham House Rule to facilitate open discourse around governance topics and the maximisation of sharing around best practice. This is a rule or principle according to which information disclosed during a meeting may be reported by those present, but the source of that information may not be explicitly or implicitly identified. ${ }^{1}$ During its first nine months of operation, Asian Legal Network round-tables have addressed the challenge speculative patent trolls can present to the Chinese market, the development of large initiatives and promises around patents in the international market, and an exploration of current trends in the field of copyright compliance.

Any discussion involving many stakeholders will tend to take a while. There are many perspectives to take into account, there is a continually evolving market to consider, and the development of consensus is a process rather than a top-down outcome. However, the Open Compliance Summit and the Asian Legal Network round-tables have already proven that collaborative dialogue around Open Source is both possible and desired in Asia, and they have set in motion a process that has been observed to result in deep and fruitful relationships both in the Americas and in Europe.

These events, primarily focused on legal strategy concerns, align neatly with older events focused more on platform development such as LinuxCon Japan, Korea Linux Forum (both Linux Foundation events) or COSCUP in Taiwan. While no single event covers all the topics of interest to a commercial stakeholder in Open Source, attending a combination of these events provides the opportunity to learn about Open Source technology, to learn how people are deploying such technology, and to understand how to balance risk and opportunity around adopted platforms.

It is probably not premature to suggest that 2015 is the year when Asian companies will be increasingly visible around development in certain platform technologies, not least those related to mobile and cloud computing. Whether considering Tizen and WebOS in Korea, Tencent or Alibaba's cloud infrastructure in China, or enterprise products from Hitachi and Fujitsu in Japan, there is a wealth of advanced technology with Asian companies positioned as lead stakeholders. It is therefore also reasonable to propose that 2015 will also be the year when governance from the perspective of community stakeholding takes deeper root in Asia. The terrific opportunity that lies ahead for the global technology industry is to maximise collaboration as this happens, and to bridge as much as possible the knowledge present in America, Europe and Asia so the most valuable ideas travel to all interested parties.

For those readers based in Asia, it is now a good time to consider whether attending the European Legal Network Conference in Spring 2016 or the Linux Foundation Member Counsel events around LinuxCon North America in Fall 2016 can fit into your schedule. For those readers based in the Americas or Europe, it is probably an excellent time to consider whether participation in a round-table in India or CJK nations (every quarter 2016) or at the Open Compliance Summit (Winter 2015/2016) aligns with your travel. As with the emergence of the European Legal Network events from 2007 onward, the increased discourse provided by new Asian events is playing an important role in connecting stakeholders, and there is substantial strategic value due to the enhanced networking opportunities and dissemination of best practice around governance. This applies equally to supply chain issues, code life cycle management, compliance and community engagement concerns.

$1 \mathrm{http}: / /$ www.chathamhouse.org/about/chatham-house-rule 
You can learn more about the Open Compliance Summit at the Linux Foundation's dedicated website:

http://events.linuxfoundation.org/events/open-compliance-summit

You can learn more about the Asian Legal Network round-tables by contacting OIN:

http://www.openinventionnetwork.com/contact-us/

This article cited several development-focused events worthy of note in Asia. These are:

Korean Linux Forum:

http://events.linuxfoundation.org/events/korea-linux-forum

LinuxCon Japan:

http://events.linuxfoundation.org/events/linuxcon-japan

COSCUP:

http://coscup.org/

\begin{abstract}
About the author
Shane Coughlan is an expert in communication methods and business development. He is well known for building bridges between commercial and non-commercial stakeholders in the technology sector. His professional accomplishments include establishing a legal department for the primary NGO promoting Free Software in Europe, building a professional network of over 270 legal counsels and technical experts across 4 continents, and aligning corporate and community interests to launch both the first law journal and first legal book dedicated to Free/Open Source Software. He spearheaded the licensing outreach that elevated OIN into the largest patent non-aggression community in history from Fall 2013.

Shane has extensive knowledge of Internet technologies, management best practice, community building and Free/Open Source Software. His experience includes engagement with the server, desktop, embedded and mobile telecommunication industries. He does business in Europe, Asia and the Americas, and maintains a broad network of contacts.
\end{abstract}




\section{Licence and Attribution}

This paper was published in the International Free and Open Source Software Law Review, Volume 7, Issue 1 (2015). It originally appeared online at http://www.ifosslr.org.

This article should be cited as follows:

Shane Coughlan (2015) 'Strategic Discourse Around Open Source in Asia', International Free and Open Source Software Law Review, 7(1), pp $13-18$

DOI: 10.5033 /ifosslr.v7i1.101

Copyright (C) 2015 Shane Coughlan.

This article is licensed under a Creative Commons International 4.0 licence, share, adapt, attribution, CCBY-4.0 available at

http://creativecommons.org/licenses/by/4.0/

As a special exception, the author expressly permits faithful translations of the entire document into any language, provided that the resulting translation (which may include an attribution to the translator) is shared alike. This paragraph is part of the paper, and must be included when copying or translating the paper.

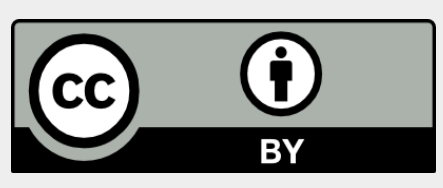

